RASĀYAN J. Chem.

Vol. 13 | No. 1 |363 - 369| January - March | 2020 ISSN: 0974-1496 | e-ISSN: 0976-0083 | CODEN: RJCABP http://www.rasayanjournal.com http://www.rasayanjournal.co.in

\title{
SYSTEMATIC LC-MS/MS METHOD FOR QUANTIFICATION OF 2,3-DIMETHYL-2H-INDAZOLE-6-AMINE CONTENT IN PAZOPANIB HYDROCHLORIDE
}

\author{
Pikkili Viswanath",", Doddipalli Venkata Ramana Reddy ${ }^{1}$ \\ and Nagaraju Chamarthi ${ }^{3}$ \\ ${ }^{1}$ Department of Chemistry, S.G.Govt. Degree and PG College, Piler-517214, \\ Andhra Pradesh, India. \\ ${ }^{2}$ Department of Chemistry, Sri Venkateswara University, Tirupati-517502, \\ Andhra Pradesh, India. \\ *E-mail: viswa_nath32@yahoo.com
}

\begin{abstract}
A sensitive and rugged method was developed and validated by using liquid chromatography coupled with triple quadrupole spectrometer (LC/MS/MS) technique for the determination of 2,3-dimethyl-2H-indazole-6-amine content in pazopanib hydrochloride. The separation was achieved by using Hypersil BDS C18 $15 \mathrm{~cm} * 4.6 \mathrm{~mm}$ length and $5.0 \mu \mathrm{m}$ width column. Mobile phase-A was $0.1 \%$ formic acid in water and mobile phase-B was acetonitrile in the ratio of $45: 55 \mathrm{v} / \mathrm{v}$ with $1.0 \mathrm{~mL} / \mathrm{min}$ flow rate in isocratic mode. The limit of detection (LOD) and limit of quantification (LOQ) signal to noise ratio values were obtained as 3.7 and 10.9 respectively. The linearity range between 0.6 to $6.0 \mathrm{ng} / \mathrm{mL}$ and the correlation coefficient was found 0.999 . The recovery found between 98.8 to $101.3 \%$ at four different levels.
\end{abstract}

Keywords: Genotoxic Impurity, Pazopanib Hydrochloride, ICH, LC/MS/MS, LOD, LOQ

(C) RASĀYAN. All rights reserved

\section{INTRODUCTION}

Pazopanib hydrochloride is a tyrosine kinase inhibitor and used for the treatment of hypersensitivity. ${ }^{1}$ The chemical name of pazopanib hydrochloride is 5-[[4-[2,3-dimethyl-2H-indazole-6-yl) methyl amino]-2pyrimidinyl]amino]-2-methylbenzenesulfonamide with $\mathrm{HCl}$ salt. The molecular formula of pazopanib hydrochloride is $\mathrm{C}_{12} \mathrm{H}_{23} \mathrm{~N}_{7} \mathrm{O}_{2} \mathrm{~S} . \mathrm{HCl}$ and molecular weight about 473.99 grams per mole. Pazopanib hydrochloride available in slightly yellow solid, practically insoluble above $\mathrm{pH} 4$ and very slightly soluble at $\mathrm{pH}$ 1.2,3-dimethyl-6-amino-2H-indazole-6-amine is used in the earlier-stage synthesis of pazopanib hydrochloride. The molecular formula of 2,3-dimethyl-2H-indazole-6-amine is $\mathrm{C}_{9} \mathrm{H}_{11} \mathrm{~N}_{3}$ and molecular weight about 161.21 grams per mole. The chemical structure of 2,3-dimethyl-2H-indazole-6-amine and pazopanib hydrochloride was shown in Fig.-1.

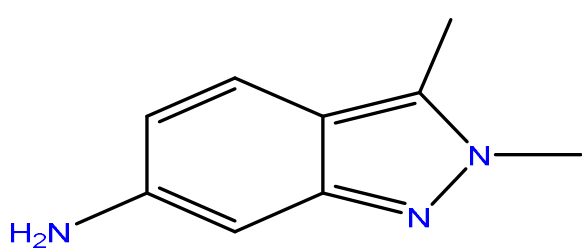

2,3-Dimethyl-2H-indazole-6-amine

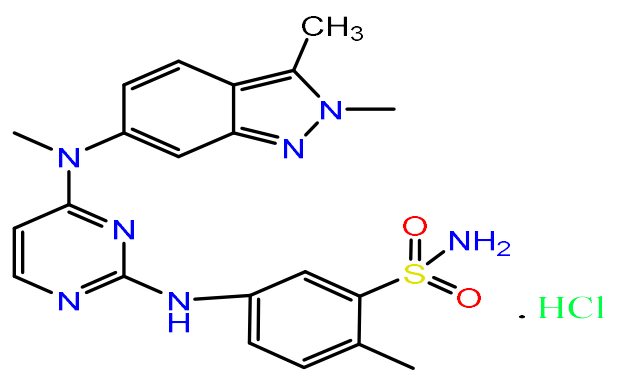

Pazopanib $\mathrm{HCl}$

Fig.-1: Chemical Structure of 2,3-Dimethyl-2H-indazole-6-amine and Pazopanib Hydrochloride

Rasayan J. Chem., 13(1), 363-369(2020)

http://dx.doi.org/10.31788/RJC.2020.1315502 
RASĀYAN J. Chem.

Vol. 13 | No. 1 |363 - 369| January - March | 2020

Pharmaceutical impurities ${ }^{2}$ are categorized into three types, they are inorganic, organic and residual solvents, those are known and unknown impurities and found during the manufacturing process of chromatographic techniques like TLC, HPLC, GC and LC/MS/MS.

2,3-dimethyl-2H-indazole-6-amine is a potential genotoxic impurity. European and ICH (International Council for harmonisation) M7 regulatory bodies expected the limit of genotoxic impurity ${ }^{3-4}$ should be below $2 \mathrm{ppm}$. There are many articles published by using LC/MS/MS technique. ${ }^{5-7}$ Usually, the term genotoxicity used in studies of in-vivo and in-vitro to find the genetic modification in genes by using a different mechanism.

\section{Chemical and Reagents}

\section{EXPERIMENTAL}

All chemicals were used above $99 \%$ purity. 2,3-Dimethyl-2H-indazole-6-amine impurity and pazopanib hydrochloride were procured from the perfomics analytical lab, Hyderabad. The formic acid, LCMS grade acetonitrile, HPLC grade water were got from the Merck life sciences.

\section{Instrumentation}

Liquid chromatography coupled with triple quadrupole is a powerful tool used extensively in the pharmaceutical and biopharmaceutical industry. Applied biosystem sciex QTRAP (Model: 4000) mass spectrometer and waters HPLC (Model: e2695) was used to carry out the analysis. Mettler Toledo (Model: XP56) microbalance was used to weigh the samples. Analyst 1.7 software on dell computer (Digital Equipment $\mathrm{Co}$ ) used for the integration and quantification of chromatographic peaks.

\section{Chromatographic Conditions}

During the method validation "Hypersil BDS C18 $(15 \mathrm{~cm}$ x $4.6 \mathrm{~mm}, 5.0 \mu \mathrm{m})$ " column was used which is manufactured by Thermo fisher scientific. The mobile phase constitutes solution-A and solution-B Solution-A was $0.1 \%$ formic acid in water and solution-B was acetonitrile in the ratio of 45:55 (solutionA: solution-B, $v / \mathrm{v}$ ). The injection volume $20 \mu \mathrm{L}$ with a flow rate of $1.00 \mathrm{~mL} / \mathrm{min}$. The program was used isocratic mode with a shorter run time of 5 minutes.

\section{Mass Spectro Meter Parameters}

The optimised parameters were temperature: $450^{\circ} \mathrm{C}$, Ion spray voltage: 5500.00 , Curtain gas: 40.0, DP: 51.0 volts, EP: 15.0 volts, CE: 27.0 volts, CXP: 16.0 volts GS1: 50.0 GS2: 40.0, CAD GAS: 8, split ration: 4:6 for 2,3-Dimethyl-2H-indazole-6-amine. Positive MRM mode was used with $\mathrm{m} / \mathrm{z}$ values 162.0 $>147.0$ for 2,3-dimethyl-2H-indazole-6-amine and the details of the respective mass spectrum of $\mathrm{m} / \mathrm{z}$ values were shown in Fig.-2 and Fig.-3.

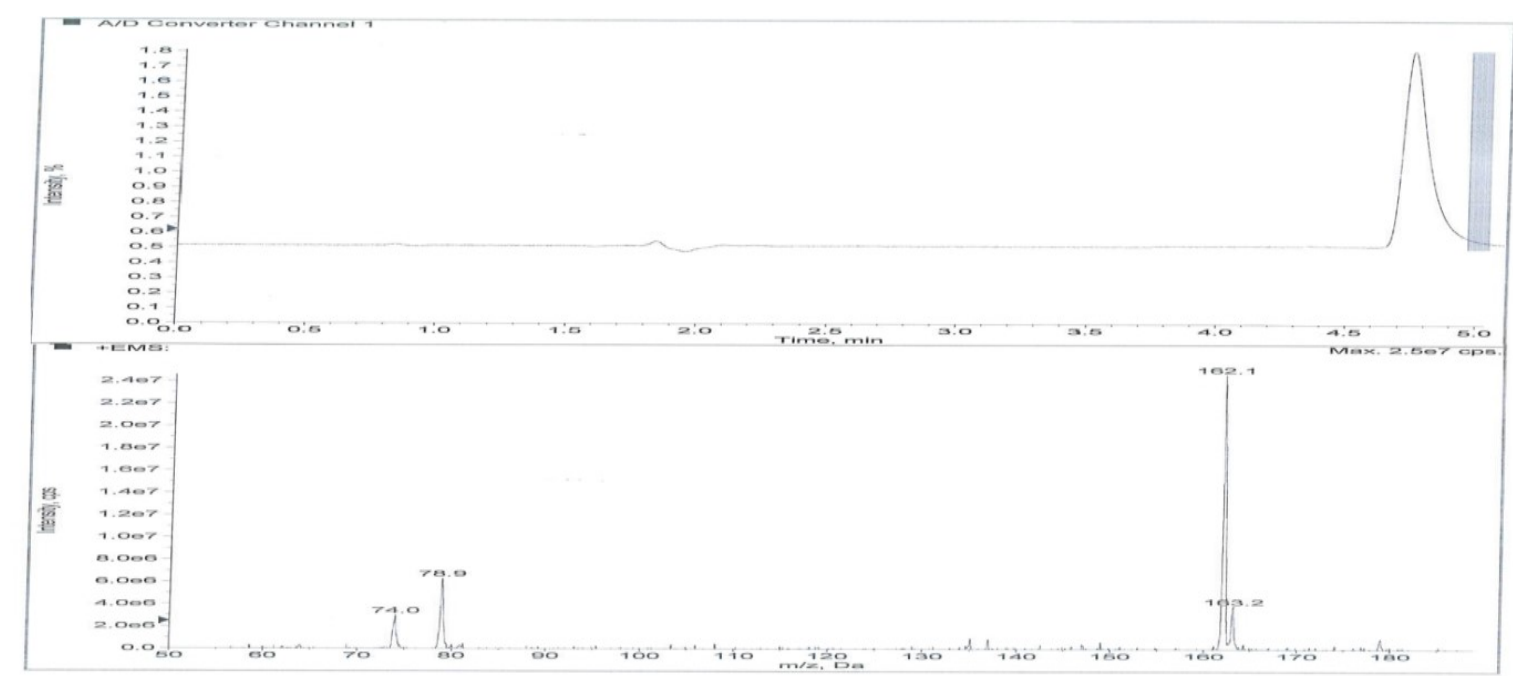

Fig.-2: Q1 Mass Spectrum of 2,3-Dimethyl-2H-indazole-6-amine 
RASĀYAN J. Chem.

Vol. 13 | No. 1 |363 - 369| January - March | 2020

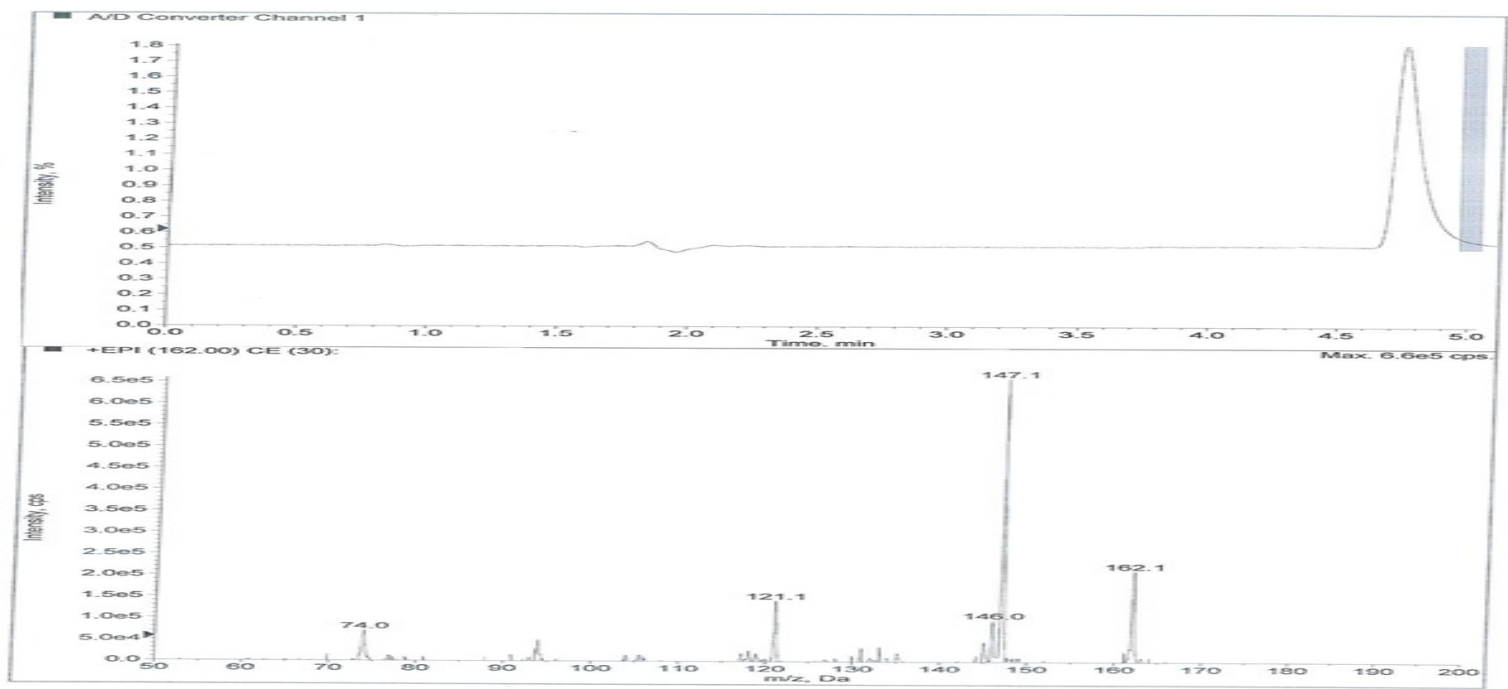

Fig.-3: Q3 Mass Spectrum of 2,3-Dimethyl-2H-indazole-6-amine

\section{Standard and Sample Preparation}

Water and acetonitrile in the ratio $40: 60 \mathrm{v} / \mathrm{v}$ used as a diluent. The standard stock solution was prepared by weighed about $10 \mathrm{mg}$ of 2,3-dimethyl-2H-indazole-6-amine standard into $100 \mathrm{~mL}$ and further $0.6,1.0$, $1.5,2.0,4.0$ and $6 \mathrm{ppm}$ concentrations samples were prepared from standard stock solution with respect to test concentration. The sample solution was prepared $1 \mathrm{mg} / \mathrm{mL}$ with diluent.

\section{Method Development}

\section{RESULTS AND DISCUSSIONS}

During the method development, many trials were performed by using the HPLC technique with different types of buffers, solvents, columns in isocratic and gradient mode. All trials were ineffectiveness to get the $6 \mathrm{ppm}$ sensitivity due to elution of unknown impurities along with desired 2,3-dimethyl-2H-indazole6-amine impurity, hence method was the switchover from the HPLC to LC/MS/MS technique to get the 6 ppm sensitivity. Different types of buffers, solvents, columns were used while performing the method development by using LC/MS/MS as a trial and error method. Finally the separation of 2,3-dimethyl-2Hindazole-6-amine and pazopanib hydrochloride by using Hypersil BDS C18 $15 \mathrm{~cm} * 4.6 \mathrm{~mm}$ length and $5.0 \mu \mathrm{m}$ width column. The mobile phase was solution-A containing $0.1 \%$ formic acid and solution-B acetonitrile in the ratio of $45: 55 \mathrm{v} / \mathrm{v}$ with a flow rate of $1.0 \mathrm{~mL} / \mathrm{min}$ in isocratic mode. The column oven temperature was $25^{\circ} \mathrm{C}$; the sample cooler temperature was $20^{\circ} \mathrm{C}$ and mass spectrometer parameters optimized to get maximum sensitivity.

\section{Method Validation}

\section{Specificity}

Initiated the method validation ${ }^{8}$ with specificity parameter by injecting diluent, 2,3-dimethyl-2Hindazole-6-amine and pazopanib $\mathrm{HCl}$ solutions. It was observed that there is no interference observed at the retention time of the 2,3-dimethyl-2H-indazole-6-amine impurity and pazopanib $\mathrm{HCl}$. The corresponding specificity chromatograms were shown in Fig.-4, Fig.-5 and Fig.-6 respectively.

\section{System Suitability}

As a part of the system suitability for checking the system was established by injecting the six replicate injections of limit level (2.00 ppm) standard solution and found the $\%$ RSD as $0.7 \%$ and details tabulated in Table-1.

Table-1: System Suitability of 2,3-Dimethyl-2H-indazole-6-amine.

\begin{tabular}{c|c}
\hline Injection No. & Area Counts of 2,3-Dimethyl-2H-indazole-6-amine \\
\hline 1 & 117569 \\
\hline 2 & 118568 \\
\hline
\end{tabular}


RASĀYAN J. Chem.

Vol. 13 | No. 1 |363 - 369| January - March | 2020

\begin{tabular}{c|c}
3 & 117041 \\
\hline 4 & 119121 \\
\hline 5 & 118436 \\
\hline 6 & 117096 \\
\hline Aveg.area & 117972 \\
\hline Std. dev. & 858.8 \\
\hline \%RSD & 0.7 \\
\hline
\end{tabular}

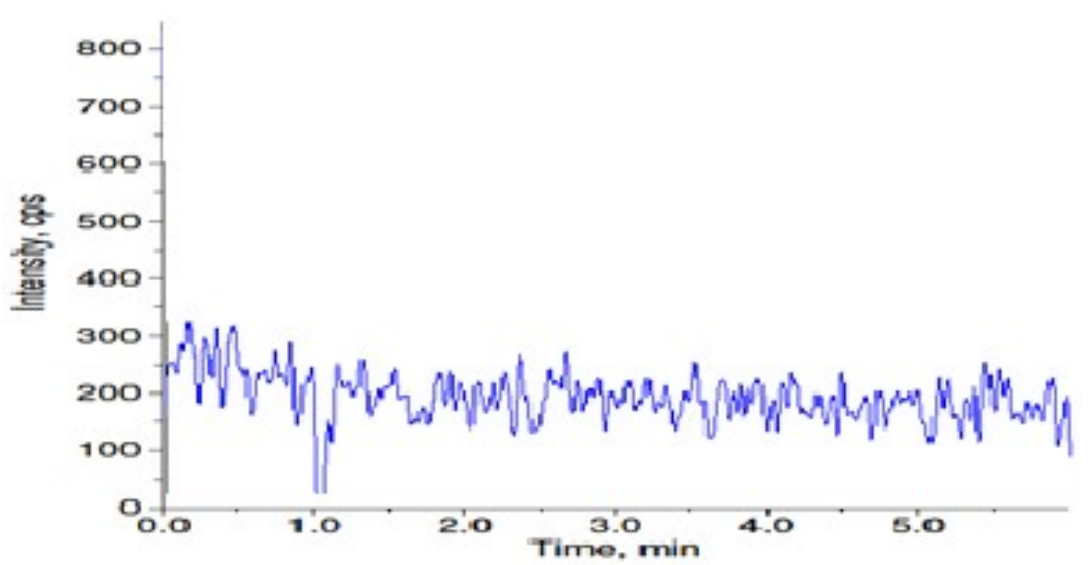

Fig.-4: Blank Chromatogram of Specificity

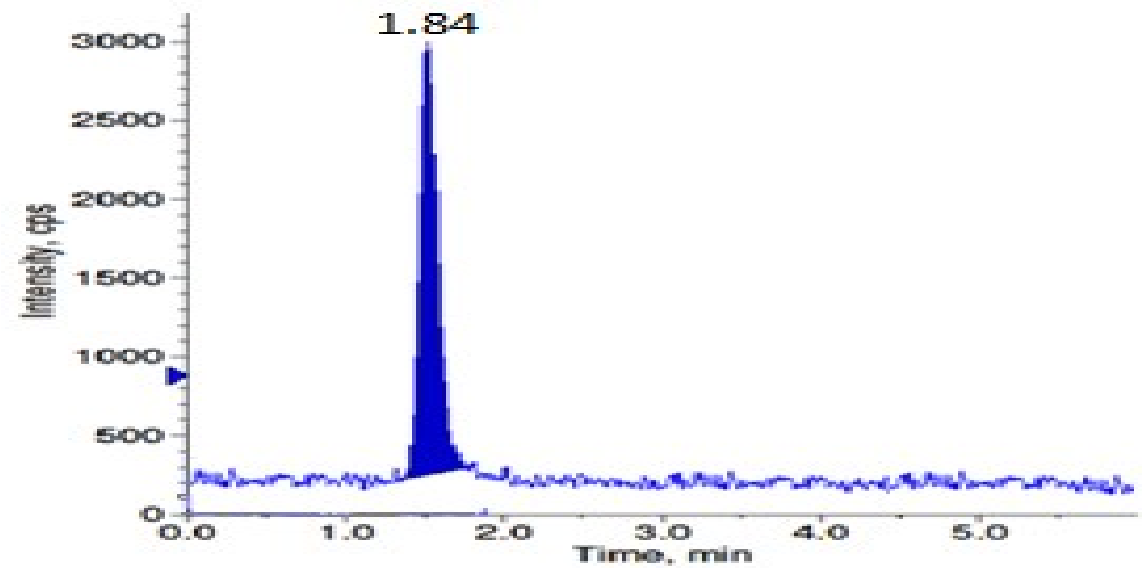

Fig.-5: Specificity Chromatogram for 2,3-Dimethyl-2H-indazole-6-amine

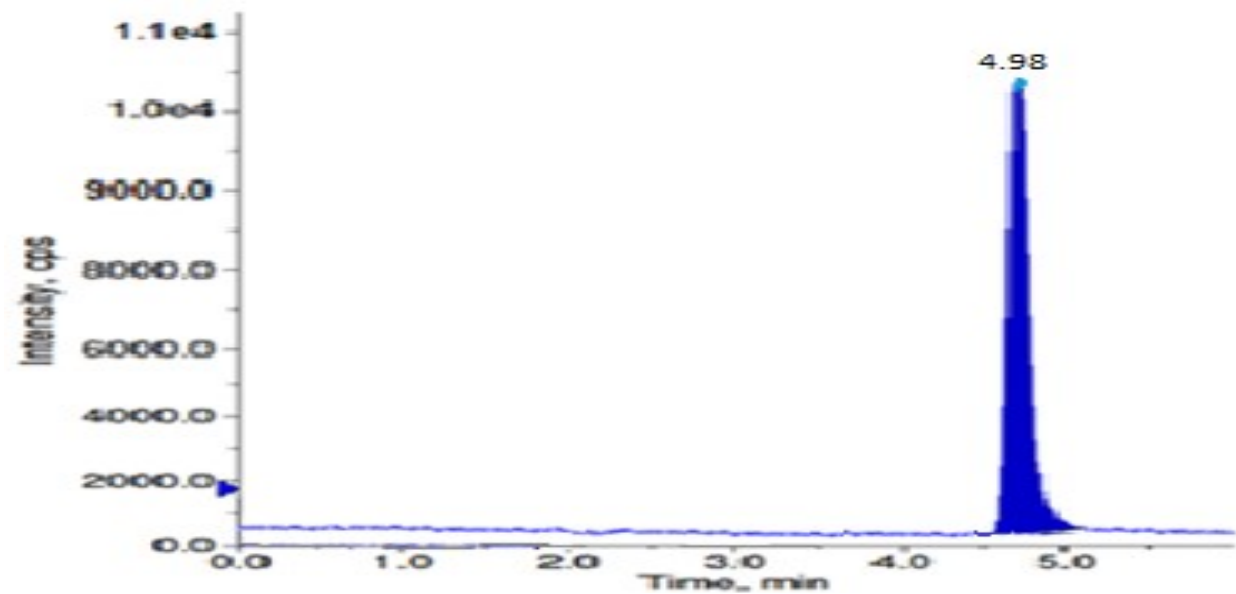

Fig.-6: Specificity Chromatogram of Pazopanib Hydrochloride 
RASĀYAN J. Chem.

Vol. 13 | No. 1 |363 - 369| January - March | 2020

\section{Determination of Limit of Detection and Limit of Quantification}

These two parameters play an important role in method validation. By injecting $0.2 \mathrm{ppm}$ and $0.6 \mathrm{ppm}$ of LOD and LOQ individual solutions of 2,3-dimethyl-2H-indazole-6-amine each with respect to the drug substance concentration of $1 \mathrm{mg} / \mathrm{mL}$ and determined their $\mathrm{S} / \mathrm{N}$ ratios and obtained $\mathrm{S} / \mathrm{N}$ values were 3.7 for LOD and 10.9 for LOQ.

\section{Linearity}

The linearity of 2,3-dimethyl-2H-indazole-6-amine was acceptable with a six-point calibration curve 0.6 , 1.0, 1.5, 2.0, 4.0 and $6.0 \mathrm{ppm}$ concentrations. The slope, intercept, and correlation coefficient values were found from linear least squares regression analysis. The correlation coefficient obtained was $>0.999$ and shown in Fig.-7. The corresponding linearity data was presented in Table-2.

Table-2: Linearity Table of 2,3-Dimethyl-2H-indazole-6-amine

\begin{tabular}{c|c|c|c|c|c}
\hline Sample Name & $\begin{array}{c}\text { Number of } \\
\text { Values used }\end{array}$ & $\begin{array}{c}\text { Mean } \\
\text { (Peak area) }\end{array}$ & $\begin{array}{c}\text { Expected } \\
\text { Concentration (ppm) }\end{array}$ & $\begin{array}{c}\text { Standard } \\
\text { Deviation }\end{array}$ & $\%$ RSD \\
\hline LOQ $(0.6 \mathrm{ppm})$ & 1 of 6 & 31681 & 0.63 & 504.2 & 1.6 \\
\hline L1 Solution $(1.0 \mathrm{ppm})$ & 1 of 3 & 62104 & 1.049 & 273.6 & 0.4 \\
\hline L2 Solution $(1.5 \mathrm{ppm})$ & 1 of 3 & 92221 & 1.574 & 663.1 & 0.7 \\
\hline L3 Solution $(2.0 \mathrm{ppm})$ & 1 of 3 & 119148 & 2.099 & 365.1 & 0.3 \\
\hline L4 solution $(4.0 \mathrm{ppm})$ & 1 of 3 & 236560 & 4.198 & 339.1 & 0.3 \\
\hline L5 Solution $(6.0 \mathrm{ppm})$ & 1 of 6 & 344188 & 6.296 & 339.2 & 0.1 \\
\hline
\end{tabular}

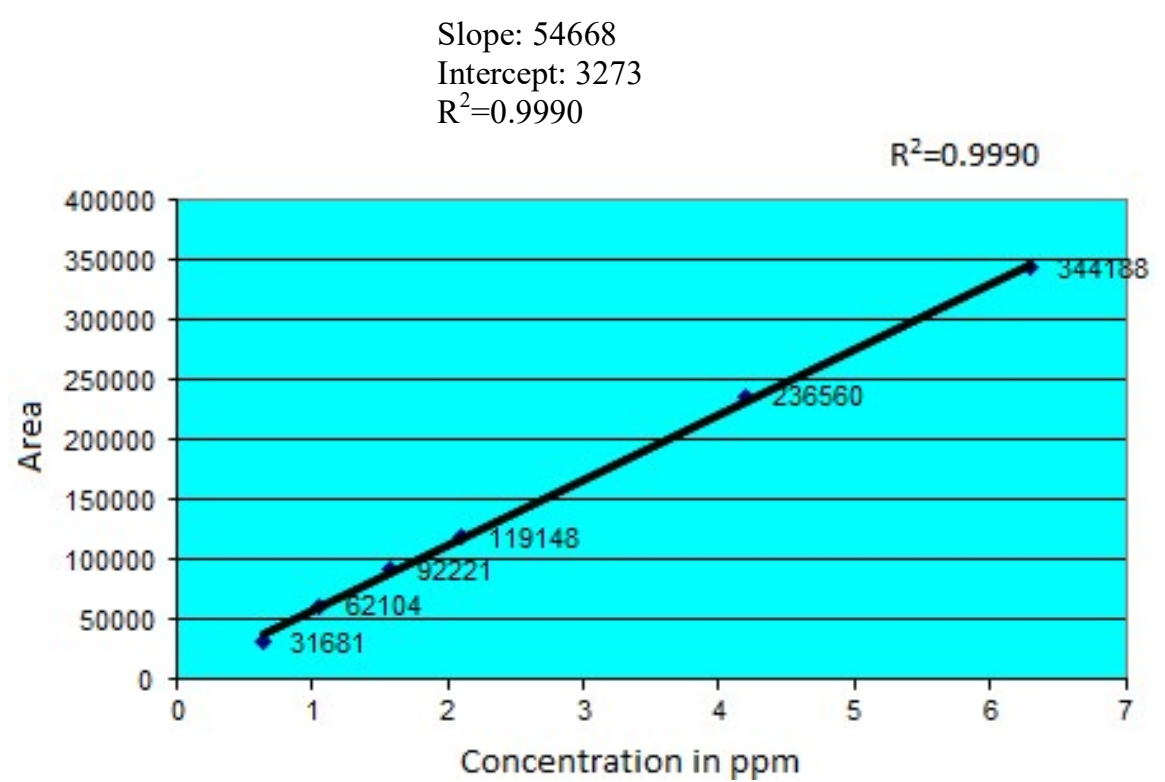

\section{Precision}

Fig.-7: Linearity Plot of 2,3-Dimethyl-2H-indazole-6-amine.

The method precision was performed by calculating the \%RSD of six individual preparations by injecting six freshly prepared solutions covering limit $(2 \mathrm{ppm})$ spiked with the sample solution. The intermediate precision was performed in different instruments on different days. The results were shown in Table-3. $\%$ RSD values were lower than $2.0 \%$ for both studies; these results confirmed an acceptable precision of the method development.

\section{Accuracy}

The recovery studies were performed from LOQ to $400 \%$, where the recovery was checked for LOQ level, L1 level (50\%) and L4 level (400\%) in triplicate injection and L2 level (100\%) in six replicate injections. The recovery was obtained for 2,3-dimethyl-2H-indazole-6-amine was between 98.8to $101.3 \%$, which indicates the method was accurate. The accuracy at LOQ chromatogram as shown in Fig.367 
RASĀYAN J. Chem.

Vol. 13 | No. 1 |363 - 369| January - March | 2020

8 and the recovery values and \%RSD were shown in Table-4.

Table-3: Intra-day and Inter-day Precision of 2,3-Dimethyl-2H-indazole-6-amine.

\begin{tabular}{c|c|c|c|c}
\hline \multirow{2}{*}{ Sample ID } & \multicolumn{2}{|c|}{ Method precision } & \multicolumn{2}{c}{$\begin{array}{c}\text { Ruggedness } \\
\text { (Intermediate precision) }\end{array}$} \\
\cline { 2 - 5 } & $\begin{array}{c}\text { Recovery } \\
(\mathrm{ppm})\end{array}$ & $\begin{array}{c}\text { Recovery } \\
(\%)\end{array}$ & $\begin{array}{c}\text { Recovery } \\
(\mathrm{ppm})\end{array}$ & $\begin{array}{c}\text { Recovery } \\
(\%)\end{array}$ \\
\hline 1 & 1.912 & 95.3 & 2.016 & 100.3 \\
\hline 2 & 1.99 & 99.2 & 2.031 & 101 \\
\hline 3 & 1.913 & 95.3 & 1.996 & 99.3 \\
\hline 4 & 1.988 & 98.8 & 2.047 & 101.8 \\
\hline 5 & 1.965 & 97.9 & 2.014 & 100.2 \\
\hline 6 & 1.967 & 98 & 1.991 & 99.1 \\
\hline Average & 1.956 & 97.4 & 2.016 & 100.3 \\
\hline Std. dev. & 0.04 & 1.71 & 0.02 & 1.02 \\
\hline \% RSD & 1.8 & 1.8 & 1 & 1 \\
\hline
\end{tabular}

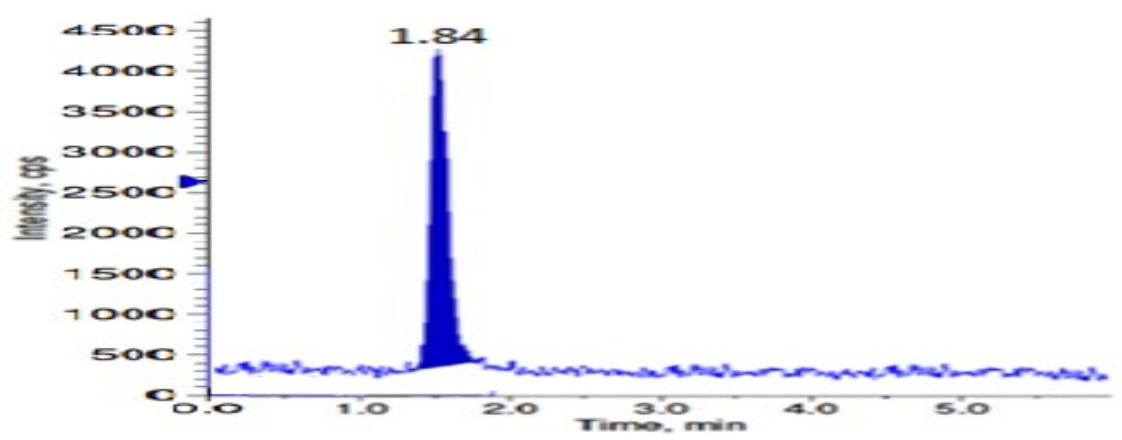

Fig,-8: Accuracy Chromatogram at LOQ Level

\section{Robustness}

The robustness was defined as the repeatability of the method shall be the same when slight changes happen in the method parameters; hence the flow rate was altered by 0.1 units from $1.1 \mathrm{~mL} / \mathrm{min}$ to 0.9 $\mathrm{mL} / \mathrm{min}$ and temperature changes from $23^{\circ} \mathrm{C}$ to $27^{\circ} \mathrm{C}$. The $\% \mathrm{RSD}$ was observed less than $1 \%$ in all conditions and results were shown in Table-5 and Table-6.

Table-4: The Recovery of 2,3-Dimethyl-2H-indazole-6-amine at Four Different Concentrations

\begin{tabular}{|c|c|c|c|}
\hline $\begin{array}{l}\text { Theoretical Conc. } \\
\text { (ppm) }\end{array}$ & $\begin{array}{l}\text { Measured Conc. } \\
(\mathrm{ppm})\end{array}$ & Recovery \% & $\% \mathrm{RSD}$ \\
\hline 0.6 & 0.5984 & 99.6 & \multirow{3}{*}{0.7} \\
\hline 0.6 & 0.6001 & 100.1 & \\
\hline 0.6 & 0.6022 & 100.3 & \\
\hline 1 & 1.0122 & 101.1 & \multirow{3}{*}{0.8} \\
\hline 1 & 1.0141 & 101.3 & \\
\hline 1 & 0.9988 & 99.9 & \\
\hline 2 & 1.9946 & 98.8 & \multirow{6}{*}{0.7} \\
\hline 2 & 1.9981 & 99.3 & \\
\hline 2 & 1.999 & 99.7 & \\
\hline 2 & 2.0069 & 100.2 & \\
\hline 2 & 2.0008 & 100.1 & \\
\hline 2 & 2.0018 & 100.4 & \\
\hline 6 & 6.0102 & 100.2 & \multirow{3}{*}{0.6} \\
\hline 6 & 6.0081 & 100.1 & \\
\hline 6 & 5.9923 & 99.9 & \\
\hline
\end{tabular}


RASĀYAN J. Chem.

Vol. 13 | No. 1 |363 - 369| January - March | 2020

Table-5: Robustness Data for Flow Rate Changes

\begin{tabular}{c|c|c|c}
\hline Injection No. & $\begin{array}{c}\text { Actual Flow } \\
(1.00 \mathrm{~mL} / \mathrm{min})\end{array}$ & $\begin{array}{c}\text { Low Flow }(0.90 \\
\mathrm{mL} / \mathrm{min})\end{array}$ & $\begin{array}{c}\text { High Flow } \\
(1.10 \mathrm{~mL} / \mathrm{min})\end{array}$ \\
\hline 1 & 117569 & 119412 & 116406 \\
\hline 2 & 118568 & 119418 & 115638 \\
\hline 3 & 117041 & 118631 & 116931 \\
\hline 4 & 119121 & 118899 & 116099 \\
\hline 5 & 118436 & 119560 & 114011 \\
\hline 6 & 117096 & 118069 & 115758 \\
\hline Avg. area & 117972 & 118998 & 1006.5 \\
\hline Std. dev. & 858.8 & 578.1 & 0.9 \\
\hline
\end{tabular}

Table-6: Robustness Data for Column Temperature Changes

\begin{tabular}{c|c|c|c}
\hline Injection No & Actual Column Temp $\left(25^{\circ} \mathrm{C}\right)$ & $\begin{array}{c}\text { Low Column Temp } \\
\left(23^{\circ} \mathrm{C}\right)\end{array}$ & $\begin{array}{c}\text { High Column Temp } \\
\left(27^{\circ} \mathrm{C}\right)\end{array}$ \\
\hline 1 & 117569 & 118544 & 118238 \\
\hline 2 & 118568 & 119056 & 119756 \\
\hline 3 & 117041 & 119985 & 118987 \\
\hline 4 & 119121 & 118406 & 118874 \\
\hline 5 & 118436 & 118963 & 118966 \\
\hline Avg. area & 117096 & 118047 & 118920 \\
\hline Std. dev. & 117972 & 118834 & 494.6 \\
\hline \% RD & 858.8 & 674.9 & 0.4 \\
\hline
\end{tabular}

\section{CONCLUSION}

A simple and rugged method was developed for the determination of trace level 2,3-dimethyl-2Hindazole-6-amine impurity in Pazopanib Hydrochloride using LC-MS/MS. Results obtained during the method validation were precise, accurate and $\mathrm{S} / \mathrm{N}$ ratio for the LOD:3.7 and LOQ:10.9 with respect to acceptable values. This method can be used in further API analysis to identify and quantify the 2,3dimethyl-2H-indazole-6-amine impurity in Pazopanib hydrochloride manufacturing.

\section{ACKNOWLEDGMENT}

The authors are thankful for the scientific support to the perfomics analytical lab, Hyderabad for providing the analytical platform to develop and validate a 2,3-dimethyl-2H-indazole-6-amine impurity LC/MS/MS method.

\section{REFERENCES}

1. C. A. Janeway, P. Travers, M. Walport, M. Shlomchik, Immunobiology, $5^{\text {th }}$ edition, New York, (2001).

2. https://www.ich.org/page/quality-quideline.

3. https://www.ema.europa.eu/en/documents/scientific-guideline-answers-guideline-limits-genotoxicimpurities_en.pdf.

4. https://www.fda.gov/media/85885/download.

5. N. Subbaiah, G. V. Subba Reddy, N. Kanyawar, M. Gangrade, Rasayan Journal of Chemistry, 10, 1080(2017), DOI:10.7324/RJC.2017.1041863.

6. A. Vijaya Bhaskar Reddy, N. Venugopal, G. Madhavi, K. Gangadhara Reddy, V. Madhavi, Journal of Pharmaceutical and Biomedical Analysis, 84, 84(2013), DOI: 10.1016/j.jpba.2013.05.047.

7. B. Mallikarjuna Rao, M. K. Srinivasu, G. Sridhar, P. Rajender Kumar, K. B. Chandra Sekhar, I. Aminul, Journal of Pharmaceutical and Biomedical Analysis, 39, 503(2005), DOI:10.1016/j.jpba.2005.04.018.

8. https://database.ich.org/sites/default/files/Q2_R1_Guideline.pdf. 